\title{
Evaluation of academic legal publications in Finland
}

\section{Letto-Vanamo, Pia}

\section{Edward Elgar}

2019-04-26

Letto-Vanamo , P 2019 , Evaluation of academic legal publications in Finland . in R van Gestel \& A Lienhard (eds), Evaluating Academic Legal Research in Europe: The Advantage of Lagging Behind . Edward Elgar, Cheltenham , pp. 218-237 . https://doi.org/10.4337/9781788115506.0

http://hdl.handle.net/10138/306422

https://doi.org/10.4337/9781788115506.00013

unspecified

submittedVersion

Downloaded from Helda, University of Helsinki institutional repository.

This is an electronic reprint of the original article.

This reprint may differ from the original in pagination and typographic detail.

Please cite the original version. 


\section{Evaluation of academic legal publications in Finland}

\section{Pia Letto-Vanamo}

\section{INTRODUCTION}

\subsection{The landscape}

Finland, with only 5.5 million inhabitants, is one of the smallest countries discussed in this book. There are four law faculties, which are all state funded. In addition, legal subjects are taught - and a doctoral thesis on a legal topic can be defended - in business schools and at faculties of administrative studies. The oldest and largest of the faculties is the faculty of law at the University of Helsinki (founded 1640). The University of Turku (founded in 1960) and the University of Lapland (founded 1979) also have law faculties. Furthermore, since 2015 the University of Eastern Finland has the right to award degrees in law. Annually, approximately 600 new students are admitted to study law in Finland. Because of the numerus clausus system - which requires the hard selection of students via entrance exams ${ }^{1}$ - hardly anyone abandons their studies and the prestige of a legal education is considerable.

The universities educate civil servants and judges for local and higher courts, as well as practising lawyers (solicitors, advocates) and legal academics. Thus, the law faculties - not the state (e.g. as in Germany), the $\mathrm{Bar}^{2}$ or an academy for judges - award the basic qualification to enter the legal profession. Here, one can easily identify reasons as to why discussions about university education in law and its reforms so often reflect the dilemma between the ideal of professional training and that of a more general academic education. ${ }^{3}$ Not only are the status and number of non-practical or 'useless' topics (e.g. legal philosophy or legal history) in the teaching curriculum discussed, but also whether the common qualification criteria - including the requirement for international scientific cooperation and publishing - should be applied when professors in law are appointed.

More than the other universities, the University of Helsinki emphasizes its role as a research university. It is an active member of the League of Research Universities and stands today as the $56^{\text {th }}$ university on the Shanghai List, but is working hard for inclusion in the top 50. ${ }^{4}$ Therefore, 'competitiveness', 'efficiency' and 'internationalization' are key terms in the university's strategy, which has a direct influence on resource allocation, recruiting procedures and even rankings between individual researchers. This strategy, with its focus on research and internationalization, also affects activities at the faculty of law, creating tension between the professional and the academic approach and between

\footnotetext{
${ }^{1}$ At the Law Faculty in Helsinki, only 6-8 per cent of candidates pass the entrance exam. At the other universities, the percentage is generally slightly higher.

${ }^{2}$ Membership of the Finnish Bar Association requires a master's degree and the passing of a bar exam.

${ }^{3}$ See further Pia Letto-Vanamo, Legal Education as a Channel to Social Elite (Scientia Danica Series H 2017) 86-101.

${ }^{4}$ It can, however, be noted, that when the positions of the Nordic universities in the international ranking lists are analysed in relationship to number of inhabitants, the Nordic countries stand at the top of the ranking.
} 
national and international orientation. At the same time, the distance between the University of Helsinki faculty of law and other law faculties is increasing. Most doctoral theses in law are defended in Helsinki and an increasing number of them are written in English. ${ }^{5}$ Nationally, the faculty's scholars are the most successful in competing for external research funding - which can be at least partly explained by international activities and the well-functioning networks of Helsinki scholars, especially in international law, legal theory and European law.

Around 80 per cent of the university budget comes from the state. The remaining 20 per cent comes from external funding of individual scholars or research groups provided by national (mainly the Academy of Finland and Business Finland ) or European (e.g. the European Research Council) research foundations, or commercial and non-commercial third parties. The Academy of Finland is the most important funding agency for Finnish legal research. Legal scholars, however, have also managed to obtain funding via private donations (e.g. from companies or law firms), as well as contracts with public bodies (e.g. government agencies) and private parties.

\subsection{Responsibility for evaluation}

Responsibility for the evaluation of academic legal research is spread between different actors. In Finland, law faculties and their research are mainly concerned with the evaluation of the individual performance and output of their academic staff. Individual articles or book manuscripts are evaluated by those responsible for publishing, research proposals submitted for funding are evaluated by funding agencies and their experts, and published research may be evaluated by committees that can grant prizes and awards, and by those who recruit or nominate scholars to academic positions.

Within the universities, the output of law faculties and legal scholars is evaluated by reference to criteria formulated by the Ministry of Education and Culture and the university administration (the university board and the rector). These criteria include educational and research indicators. The former are quite favourable towards law faculties, because of the effective 'production' of the number of bachelor's and master's degrees. The - less favourable - indicators in assessing research outputs include the number of doctoral degrees, the amount of external research funding and the number of (ranked) publications. ${ }^{6}$ The universities also have their own 'output guiding' systems. The University of Helsinki rewards faculties and their research according to the ministry's criteria, but awards larger amounts than under the ministry model for success in obtaining external research funding, which means that faculties and researchers in the science fields are better funded than those in social sciences and humanities.

\subsection{Ranking of legal publications by Publication Forum}

Since 2010, the key actor in the evaluation of academic publications has been the so-called 'Publication

\footnotetext{
${ }^{5}$ In 2015, 23 theses were defended, 13 of which were in English. The second most productive law faculty is that at the University of Turku, where the figures were ten and two, respectively.

${ }^{6}$ For more details see the Statute of Funding for Universities (526/2014).
} 
Forum' (in Finnish, often referred to as 'JUFO' from the Finnish word 'Julkaisfoorumi'), operating under the auspices of the Federation of Finnish Learned Societies. The Publication Forum has created a rating and classification system (inspired by the systems in Norway and Denmark) to 'support the quality assessment of research output'. At the same time, the classification is meant to 'encourage Finnish scholars and researchers to publish their research outcomes in high-level domestic and foreign forums' ${ }^{7}$ The classification includes academic journals, book series, conferences and book publishers. The three-level classification rates the major foreign and domestic publication channels of all disciplines, with 1 being the basic level, 2 the leading level and 3 the highest level. ${ }^{8}$

The evaluation of publications is performed by 23 discipline-specific expert panels composed of approximately 200 distinguished Finnish or Finland-based scholars. Panel 19 evaluates publications in law, criminology and political science. ${ }^{9}$ Hence, the panel system was created to respect the specific characteristics of the publication practice in various academic fields - as opposed to, for example, citation analyses based on data in international databases. Consequently, journals in law or in (Finnish) history published in the Finnish or Swedish language can be rated at level 1 or 2; while the Finnish journals, by definition (see below), do not match with the highest level.

Only academic publication channels are eligible for Publication Forum classification. The term 'academic publication channel' refers to book publishers, conferences as well as printed and digital publication series specialized in the publication of scientific or scholarly research outcomes. The channels must have an editorial board composed of experts and follow the peer review practice. When evaluating the quality of publication channels, panels must consider the publication practices typical in their research fields (especially publication language), as well as the current standing of the respective channels within the scientific community. Thus, the third level indicates that publications in these channels are highly valued among the international research community in the field.

At the same time, panels should ensure the equal presence of various disciplines in the higher quality levels and respect quotas for level 2 and level 3 publications, which are decided by the advisory board of the Publication Forum. To support their work, panellists can utilize a number of different impact indicators and indexing data (e.g. Scopus), as well as data on the levels awarded in the corresponding Norwegian and Danish systems. Panellists are also instructed to consult their background communities, especially during the review of ratings (every fourth year). The consultation is voluntary and generally includes informal communication between panel members and scholars in respective disciplines or research fields.

Level 1 can be awarded to domestic and foreign journals, conferences and book publishers considered - according the guidelines of the Publication Forum - to be the most important from the Finnish

\footnotetext{
7 Julkaisufoorumi, 'Publication Forum' (Julkaisufoorumi, 12 May 2016), accessed September 2018 at www.julkaisufoorumi.fi/en/publication-forum.

${ }^{8}$ Classification level 0 also exists, for publications that do not meet all of the criteria (especially peer review) necessary to be classified as a level 1 publication, but can still be classified as academic publication channels.

9 The author of this article was the chair for Panel 19 from 2014-17.
} 
research perspective. However, a publication channel which meets the criteria of an academic publication channel is not included in level 1 if over half of the referees and authors represent a single research organization (e.g. publication series or doctoral dissertation series of universities and research institutes); and/or if the relevance or quality of research, evaluated quite roughly by the panellists, raises questions. Twelve Finnish legal journals or other publication series are currently at level 1.

Level 2 includes separate criteria for international publications and for Finnish and Swedish ${ }^{10}$ (as the second official language of the country) publications. The international group includes publication channels where the editors, authors and readers represent various nationalities; for this group, level 2 can be awarded to 'leading academic publication channels of various disciplines, within which researchers from various countries publish their best research outcomes'. ${ }^{11}$ However, all publication channels meeting the criteria are not necessarily included in level 2 . The panels must choose, within the framework of their level 2 quota, the publication channels to which the highest-level publications are directed as a result of extensive competition (e.g. the number of accepted/submitted papers) and which conduct the most demanding peer reviews.

In the humanities and social sciences (including law), level 2 can also include leading Finnish or Swedish-language publication channels which cover research specializing in aspects of Finnish society, culture or history in their particular field as widely as possible. Thus, publishing in these channels is 'seen to be as important merit as publishing in an international level 2 channel'. ${ }^{12}$

Still, certain minimum criteria are set for proposed level 2 Finnish/Swedish publication channels:

- The quality assessment of the scholarly writings must be in line with best practices (referring to double-blind review);

- The publication series ${ }^{13}$ must cover research in the respective discipline most widely and be used by the entire national research community in the discipline; and

- The context of the research problems must be strongly focused on Finnish society or the Finnish or Swedish-speaking culture.

Thus, as with the international group, not all publication channels meeting these criteria are automatically rated at level 2. Only a selection of the highest-quality, most comprehensive Finnish and Swedish-language publication channels covering disciplines in which it is justified to produce and publish new research in the national languages are included. In addition, the rating is based on a joint consensual decision of the chairs of the social sciences and humanities panels. Two legal journals (Lakimies, published by the Finnish Association of Lawyers; and Oikeus, published by the Association

\footnotetext{
${ }^{10}$ Every year 25-35 (as a quota) students with Swedish as their first language are accepted to the faculty of law at the University of Helsinki, which is the only bilingual university in the country.

${ }^{11}$ Julkaisufoorumi, 'Publication Forum' (Julkaisufoorumi, 12 May 2016), accessed September 2018 at www.julkaisufoorumi.fi/en/publication-forum.

12 Julkaisufoorumi, 'Publication Forum' (Julkaisufoorumi, 12 May 2016), accessed 12 September 2018 at www.julkaisufoorumi.fi/en/publication-forum.

${ }^{13}$ As well as book publishers in their main disciplines.
} 
of Legal Policy) are currently rated at level 2.

Level 3 includes the highest-level publication channels in various disciplines which meet the following requirements:

- The research they publish represents the highest level in the discipline and has an extremely consistent impact (in natural sciences, this is mostly measured through citation indicators);

- The channels cover the discipline comprehensively and are not limited to the discussion of narrow specialist themes;

- The channels have international authors and readers, and the editorial boards are comprised of the leading researchers in the field; and

- Publications in these channels are highly valued among the international research community in the field.

American Journal of Comparative Law, Common Market Law Review and The European Law Review are examples of current level 3 legal journals. ${ }^{14}$ Hence, the criteria as well as the quota system are favourable to law journals published in English, ${ }^{15}$ in which competition between authors is more intense, peer review procedures are usually more demanding and publication volumes are bigger than, for example, in German law journals. ${ }^{16}$

The so-called 'quota system' again does not per se indicate quality, but quite formally determines how many publication channels each panel can classify at levels 2 and 3. Since 2015, the quota calculation criterion has been the publication volume (meaning the number of issues and pages per year) of the channel in question, not the number of titles. Therefore, the number of publication channels in levels 2 and 3 varies between panels. Thus, 'publication volume' refers to the aggregate three-year average of domestic and foreign scholarly articles in the series or conference proceedings. The volume-based quotas were introduced because in certain areas of science and medicine, the volume of submissions to the leading publication channels has allowed them to grow very large. One-fifth of these titles may publish over one-half of the articles produced in the relevant discipline. In social sciences and humanities, on the contrary, corresponding differences in volume between the basic and best journals do not exist. Thus, the combined publication volume of the series rated as level 2 can be a maximum of 20 per cent of the aggregate publication volume (levels 1-3) assigned to the panel in question. The combined publication volume of the series rated as level 3 can be a maximum of 25 per cent of the aggregate level 2 publication volume assigned to the panel in question.

In the data collection procedure of the Ministry of Education and Culture (and the universities),

\footnotetext{
${ }^{14}$ The others are American Journal of International Law, European Journal of International Law, European Law Journal, Harvard International Law Journal, Harvard Law Review, International and Comparative Law Quarterly, Journal of Law and Society, Law and Philosophy, Law and Society Review, Oxford Journal of Legal Studies, The Modern Law Review and Yale Law Journal.

15 This is also true of book publishers: all level 3 publishers (e.g. Oxford University Press and Cambridge University Press) that (also) publish legal books publish only in English.

${ }^{16}$ Which are often specialized in only one legal field.
} 
individual articles or books are rated according to the publication type awarded to the article (A1 meaning refereed journals etc) or book in question. ${ }^{17}$ In the current university funding model, the coefficient of the relevant Publication Forum level is applied only to peer-reviewed scientific or scholarly articles in journals, conferences and compilations, as well as to scholarly books (not including textbooks or popularized books). Starting from 2017, publications relevant to the ministry's university funding model are weighted using the following coefficients based on the type of publication and the Publication Forum level. Non-scholarly/academic (as 'non-refereed') articles and books are rated in the model, but with a much lower coefficient.

\begin{tabular}{|c|c|c|c|c|c|}
\hline \multirow{2}{*}{\multicolumn{2}{|c|}{ TMPE OF PUBUCATION }} & \multicolumn{4}{|c|}{ COEFIOENT / LEVE } \\
\hline & & LEVEL 3 & LFVEL 2 & LEVEL 1 & LEVEL 0 \\
\hline \multirow{3}{*}{ REFERED } & Articles (A1-A4) & 4 & 3 & 1 & 0.1 \\
\hline & Monographs (C1) & 16 & 12 & 4 & 0.4 \\
\hline & Editing of a scholarly book (C2) & 4 & 3 & 1 & 0.1 \\
\hline \multirow{2}{*}{ NON-REGREED } & $\begin{array}{l}\text { Articles and other (B, D1-D4, } \\
\text { D6, E1, E3) }\end{array}$ & \multicolumn{4}{|c|}{0.1} \\
\hline & $\begin{array}{l}\text { Textbooks and popularised } \\
\text { books (D5, E2) }\end{array}$ & \multicolumn{4}{|c|}{0.4} \\
\hline
\end{tabular}

Table 8.1 Ranking of legal publications by Publication Forum

\subsection{Criticism of the ranking system}

As previously noted, the Publication Forum classification was created to respond to the need to evaluate the research output of universities and other institutes, not only quantitatively, but also qualitatively. Hence, the classification was meant to be suitable for macro-level discussions about the publication production of research organizations, research fields or the country as a whole. Since 2015, the classification has been used as a quality indicator of the research output produced by universities within the university funding model established by the Ministry of Education and Culture. Among the appropriation criteria, publications account for 13 per cent of the basic funding to universities.

Since the level awarded to a publication channel mirrors the average level of its published articles - not necessary the quality of an individual article - it is rational to use the classification to evaluate large publication volumes only. Therefore, the classification was not intended to evaluate the merits of an individual researcher; nor can it replace an assessment made by experts in a specific field in, for example, recruitment situations. Nonetheless, the classification is often applied in decisions on research funding and in university recruitment. This is the main criticism of the Publication Forum rating system: it is applied, contrary to the reason for its creation, to assess individual applications for academic

${ }^{17}$ As well as the series, conference or book publisher used as the publication channel. 
positions and research funding, and even decisions on travel grants within a university or faculty. In general, the system encourages researchers to publish in international journals and with foreign publishers; but in law, it automatically favours scholars working in international legal fields, such as comparative law, European law, international law and legal theory. At the same time, publishing increasingly in languages other than Finnish and Swedish - primarily in English - may in the long run impoverish legal scholarship written in the national languages.

The large number and variety of publication channels to be evaluated by the panel members necessarily make assessments relatively superficial. For instance, to date, around 400 publications in law have been rated by the Publication Forum and the rating is reviewed every fourth year. From January to August 2017, Panel 19 (for political science and law) rated 57 new channels. Fifteen of these were proposed to the panel by researchers in the respective disciplines. The other 42 channels the panel received through data collection performed by the Ministry of Education and Culture (on the basis of the annual reports of the universities). However, the main criterion to be accepted into level 1 is the use of a peer review system, which is quite easy to assess, but only formally. The quota system can also lead to a 'false' level - for example, because of the (percentage) quota decided by the Publication Forum adviser board for a four-year rating period, all of the best channels cannot automatically be included in level 3 . Furthermore, it is impossible to exclude the possibility that the individual interests of panellists and research trends may play a role in the assessment process. This especially concerns humanities and social sciences, where the assessment is less 'mathematical' and more substantial - and even personal - than in the sciences. ${ }^{18}$

The Publication Forum system has also increased legal scholars' interest in publishing journal articles instead of monographs, which can be seen as a positive impact - at least where publication frequency and topical academic or professional debates are concerned. At the same time, peer review is more often regarded as a daily feature of academic publishing. That said, in a small country with an exotic language, practical problems naturally arise: it is not always easy to find at least two external and neutral reviewers, and the review is seldom totally blind. However, to unify peer review practices, the Federation of Finnish Learned Societies in 2014 created a label for peer-reviewed scholarly publications. Use of the label is monitored and grant of the right to use the label confirms that research papers are subjected to peer review conducted by at least two independent referees. Only two law journals - classified at Publication Forum level 2 - currently have this label.

\section{THE EVALUATION OF LEGAL PUBLICATIONS WHEN UNIVERSITIES ARE BEING ASSESSED}

Finnish universities are not systematically evaluated. Their funding comes mainly from the state budget,

\footnotetext{
${ }^{18}$ On this criticism, see, for instance, Mirka Saarela, Tommi Kärkkäinen, Tommi Lahtonen and Tuomo Rossi, 'Expert-based versus citation-based ranking of scholarly and scientific publication channels' (2016) 10 Journal of Informetrics 693.
} 
and political discussions about the role, profile (including research areas) and quality of education and research at individual universities are mainly connected to state financing and general educational and university politics. Universities, however, have organized evaluations by themselves, usually by inviting an external panel to assess the teaching or research at the university concerned. The last research evaluation at the University of Helsinki was undertaken in 2012. Unlike the 2008 evaluation, the 2012 evaluation did not compare faculties and their research with each other, but took into account each discipline while acknowledging their special characteristics. However, the evaluators were from foreign universities, without any knowledge of the Finnish language, and the evaluation and communication language was English. Therefore, publications written in Finnish - still common in law - could not be (substantially) evaluated, but were nevertheless included in the statistics on research activities. However, publications played a central role in the evaluation procedure, as well as with respect to recommendations for the future. This can be seen in the evaluation reports written on the basis of the self-evaluation of faculties and other research units, statistics on publications, doctoral dissertations, number of academic staff, and amount and type of research funding, and on site visits with meetings and interviews.

The following comments were made about the research at the faculty of law:

'The Faculty is performing well in terms of external competitive funding and in terms of overall numbers of publications and in societal impact activities, but is recommended that more comprehensive plans of internationalization of the research are made. This concerns plans for increased international participation for all researchers, and for increased international publications, particularly in top or good journals..., ${ }^{19}$

The faculty-specific conclusions were mainly on 'internationalization' through publications:

'The Faculty has had great achievements in external funding and has created research centers of high quality in areas of current interest and need of further research. It has combined legal research with work on the theoretical, social and cultural underpinnings of law. This has resulted in research of high quality. The high quality international research does however rely on a too small number of persons. The number of international publications particularly in good and top international journals is far too low. The research centers and their international affiliations should enable an increased international activity in terms of more international publications. There could also be more publication in Nordic journals.'

\footnotetext{
${ }^{19}$ Seppo Saari and Antti Moilanen (eds), 'RC-Specific Evaluation of Law -Researchers at the Faculty of Law' (2012) 20, accessed September 2017 at www.helsinki.fi/julkaisut/aineisto/rc_evaluation2012/hallinnon_julkaisuja_80_125_2012.pdf.
} 
Legal research at the faculty of law of the University of Turku - the second largest law faculty - has also been evaluated. The evaluation report ${ }^{20}$ - which covers the period 2010-13 - contains comments and recommendations on doctoral education, international mobility and cooperation, as well as on publication practice and policy. The recommendations on publications reflect not only the problems that legal scholars may face in publishing internationally, but also the difficulties of these kinds of evaluations:

'The most important publications enumerated by the Faculty certainly belong to the top layer of Finnish publications in law, and many are also at the forefront of the discipline in international perspective.

It is difficult to assess the performance of the whole Faculty based on these top publications, as researchers only to a limited extent have performed in research groups, and much of their research output remains individual up to now. It is difficult, almost impossible, to carry out a more thorough assessment of the scientific quality of the publications based on only the list of publications in the self-evaluation report without systematic external peer review. Moreover, the ranking of the scientific journals and publishing houses where they are published is of course relevant. The bibliometric analysis will hopefully contribute to the evaluation of the scientific quality of the research.

Fewer than $25 \%$ of the publications seem to have been submitted for per review assessment and the share of international publications of the Faculty's total number of publications is limited as are publications in high-ranked publication channels.

Consequently, there is substantial room for improvement, something that the Faculty seems to take seriously and it has, among other things, started a process for adapting to the Finnish Publication Forum system for quality classification of scientific publication channels.

The Faculty has in place a policy of continuous improvement of its publications policy, and we applaud that they have identified this as a central challenge in the Research Roadmap.

The fact that the Panel has identified a need to increase the rate of publication in international peer reviewed journals should not be interpreted as meaning that all publications, or even the

\footnotetext{
${ }^{20}$ Thomas Wilhelmson, Christina Moëll and Jo Shaw, 'RAE 2015 of the University of Turku. Peer-Evaluation Report' (2015), accessed September 2017 at www.utu.fi/fi/Tutkimus/tutkimuksen-

kokonaisarviointi/arviointiaineisto/vertaisarviointi/Documents/law/oikeustieteellinen_tdk.pdf.
} 
overwhelming majority, should be in this format. The Faculty of Law, like other social sciences, has a duty to serve their domestic society in its own languages.

Furthermore, the Faculty is already aware of the fact that writing good English for publication requires both practice and appropriate support.'

The next research evaluation at the University of Helsinki, including law, will take place in 2019. Again, the number and quality (according to publication channel) of publications will be in focus. Since the last evaluation, the number of legal publications written in English has increased - likely not because of the former evaluators' recommendations, but more because of the impact of the Publication Forum system, changes to the university's recruitment policy and the general trend for writing doctoral theses more often in English than in the national languages.

\section{THE EVALUATION OF LEGAL PUBLICATIONS FOR REACHING A DECISION ABOUT PUBLICATION}

Legal publications are evaluated by, or on behalf of, journal editors and publishers. In Finland, there are around 17 law journals, of which three to five can be regarded as general interest journals, with the others being specialized in certain legal areas, such as administrative, tax and environmental law. While journals and publishers focus on publications in Finnish, only one journal is published in Swedish and few publish both in Finnish and in Swedish. Recently, some journals have also started to publish articles written in English. ${ }^{21}$

As noted, there are two Finnish journals classified at Publication Forum level 2. Twelve are in level 1, implying that they publish academic articles, have an academic editorial board and have a peer review system organized in accordance with 'good review practices' (referring to the use of independent/blind reviews). Some journals - such as Defensor Legis, which is published by the Finnish Bar Association - have introduced a separate section in which academic and peer-reviewed articles are published. This again is an important incentive to researchers who are thinking about their academic merits and future recruitment or funding competitions. At the same time, contributing to professional journals has become less popular among legal scholars. This especially concerns younger scholars competing for academic merits. Again, some elder scholars who are unfamiliar with the peer review system seem reluctant to submit papers to journals where their texts might be commented on and criticized, potentially even by younger colleagues.

\footnotetext{
${ }^{21}$ The journal Liikejuridiikka, founded in 2016, publishes articles on business law in both Finnish and English. Helsinki Law Review is edited by law students at the University of Helsinki and publishes articles in Finnish, Swedish and English. Electronic journal NoFo - No Foundations - publishes articles only in English; accessed September 2018 at http://nofoundations.com.
} 
The way in which scholarly works submitted for publication are evaluated differs depending upon the journal or publisher. Until recently - that is, before the founding of the Publication Forum - the main method of evaluation was 'editorial review', which means that either the whole editorial board read all submissions or there was a division of labour among the editors. Even today, submission guidelines are not very specific and mainly focused on formalities. Editorial boards seldom provide guidance on how exactly they reach their publishing decisions. Furthermore, only one legal journal (Lakimies) refers to substantial criteria in its submission guidelines, which are directed at both authors and reviewers. The guidelines emphasize the high academic quality and scientific novelty of each article, as well its structure and clarity. ${ }^{22}$

As stated previously, Finland's scholarly legal community is very small. Most experts in a certain field probably know each other's research interests and writing style so well that anonymity would be hard to guarantee, even with double-blind peer review. At the same time, several journals publish frequently and receive relatively few submissions, which limits the extent to which peer reviewers and editors can be critical about the quality of submitted papers, because the journal needs content to publish.

\section{THE EVALUATION OF DOCTORAL DISSERTATIONS}

Finnish legal academia does not have the PhD system that is common in other European countries. Law faculties grant the degree of doctor of laws (LLD) after completion of theoretical and substantial studies and successful defence of a thesis. Annually, 30 to 40 doctoral degrees in law are awarded, which is much more than 10 or 20 years ago. It is also possible that a candidate with no faculty funding (generally for four to five years) may obtain the right to pursue postgraduate studies and become a doctor of laws. Until recently, the doctoral thesis in law included the writing of a monograph (of approximately 320 pages), written in Finnish or Swedish and published before the defence by a commercial publisher specialized in legal (professional and academic) publications. Today, nearly half of all doctoral theses are written in English, printed in the faculty thesis series and quite often published after the defence as a new, edited version by an international publisher. ${ }^{23} \mathrm{~A}$ small number of theses are so-called 'article dissertations', based on articles published in international or national legal journals and with a summary of 50 to 100 pages, which is the most important subject discussed during the defence.

In general, Finnish doctoral dissertations in law are theoretically and substantially quite ambitious and of a higher academic quality than, for instance, dissertations at Danish or Swedish law faculties. This can mainly be explained by tradition: the general theoretical orientation of the Finnish legal university

\footnotetext{
${ }^{22}$ With respect to the publication of books, the situation is different. Only one publisher, Suomalainen Lakimiesyhdistys (Finnish Lawyers' Association), publishes exclusively academic legal books and uses at least a kind of peer review before deciding whether to publish a book. In general, non-academic books, such as commentaries and textbooks, sell better, with the market for purely academic books being very small.

${ }^{23}$ At the moment, typically by Routledge.
} 
education and legal scholarship. ${ }^{24}$ The LLD also enjoys considerable prestige outside of academia. Often, higher officials (e.g. the parliamentary ombudsman or the chancellor of justice) and judges hold LLDs. The general tendency today, however, is to increase effectiveness and to reduce the time taken for doctoral studies, which may also affect doctoral studies in law.

However, all doctoral dissertations must meet the same scholarly criteria. At the University of Helsinki, the criteria and the assessment procedure were decided by the university rector in June 2017. Similar criteria also seem to be applied at the other Finnish universities. Dissertations must:

- contain new scientific knowledge;

- demonstrate critical thinking;

- demonstrate profound knowledge of the field;

- demonstrate mastery of appropriate methods and the ability to apply them in practice;

- be academically convincing;

- contain well-grounded research results; and

- demonstrate academic integrity and follow the norms of ethical research.

In assessing the quality of doctoral dissertations in law, the following criteria should be applied: ${ }^{25}$

- the appropriateness of the research question and the professional and academic relevance of the research problem (particular attention will focus on the originality/innovativeness of the research);

- scholarliness and the mastery of required research methods (attention will be paid to the types of abilities and qualifications that completion of the research task has required. Here, 'scholarliness' refers to both sufficient expertise in the research field and wider erudition in one's discipline);

- practical implementation of the research (e.g. under assessment are the functionality of the structure of the work, the scope of the topic and the level of writing of the work, including style;

- the results of the research and their novelty, reliability and significance (characteristic of the science of law is that research results and the research process are often inseparable, because the research deals with interpretation and its justifiability. This further raises the significance of overall assessment); and

- the doctoral candidate's ability to defend his or her research in the public examination (the presentation process of a doctoral dissertation requires that the author defend his or her research in a public examination in an appropriate manner).

\footnotetext{
${ }^{24}$ See in more detail Pia Letto-Vanamo, 'Meanings(s) of Social Justice in the Nordic Countries' in Hans-W Micklitz (ed), The Many Concepts of Social Justice in European Private Law (Edward Elgar Publishing 2011) 257-276.

${ }^{25}$ Seehttps://www.helsinki.fi/en/faculty-of-law/research/doctoral-education/instructions-of-examining-doctoraldissertations\#section-44709, accessed December 2018
} 


\section{THE EVALUATION OF RESEARCH PROPOSALS AND PRIOR PUBLICATIONS BY FUNDING AGENCIES}

External competitive funding today plays a central role in the evaluation of the quality of academic institutions and individual researchers. Legal scholars are also increasingly applying for funding of research proposals from different organizations. The biggest funder in Finland is the Academy of Finland, which has similar functions, as well as a similar state budgetary basis, to national research councils in many other countries. Academy funding can be characterized as 'competitive', which means that supposedly (only) the best projects receive funding. The major research projects (e.g. centres of excellence, projects with several post-doctoral researchers, academy research fellowships, academy professorships) in law are funded by the Academy of Finland. Minor projects are generally funded by private foundations and sometimes also by public institutions. All organizations apply their own guidelines and criteria for funding, often on a case-by-case basis. This chapter focuses on the Academy of Finland criteria, which are also widely applied by other organizations.

The Academy of Finland has a well-developed and quite transparent evaluation system (applied in all disciplines) that has also had impact outside the academy. Even the quality of research plans of new doctoral candidates at the University of Helsinki is partly evaluated with regard to the Academy of Finland criteria. Funding decisions are based on a review of the scientific merits of research plans, action plans and applicants. The following criteria are used when reviewing scientific merits:

- $\quad$ scientific quality;

- innovativeness and novelty of the research plan;

- scientific impact of the research;

- competence of the applicant and the research team;

- feasibility of the research plan;

- quality and strengthening of the research environment;

- international and national research collaborations;

- researcher mobility; and

- project's significance for the promotion of professional research careers.

An application is reviewed by an external expert panel $^{26}$ (or at least two written reviews by external experts) on a rating of 1-6 (with 6 being the highest), in a number of discrete categories, covering:

- the quality of the research plan;

- the competence of the applicant and the quality of research collaborations; and

- $\quad$ overall assessment. ${ }^{27}$

\footnotetext{
${ }^{26}$ The panel members and individual experts are selected by the respective council of the Academy of Finland.

${ }^{27}$ For more detail see, for example, Academy of Finland, 'Instructions for Reviewing Research Applications Individual Reviewers' (2018), accessed November 2018 athttp://www.aka.fi/en/review-and-fundingdecisions/how-applications-are-reviewed/guides-for-reviewers/
} 
The number and quality of (published and planned) publications play an important role in assessing the competence of the applicant. They also play a role in assessing the implications of the research plan. The Academy of Finland has created a model for the list of (published) publications with categories for peer-reviewed scientific articles, non-refereed scientific articles, scientific monographs, publications intended for professional communities, publications intended for the general public, publications linked to the applicant's research and theses (including doctoral theses). The planned publications shall be presented in the research plan, but the 'promises' are evaluated as a part of the final report of the research respective research project.

Law sits within the Research Council for Culture and Society. While the evaluation criteria do not differ between research areas, the group of people who ultimately decide where the funding goes does differ - presumably because they are best placed to determine questions relating to, among other things, quality and innovativeness. In general, the external experts or panellists assessing the applications of legal academics are legal researchers who are not employed at a Finnish university, which means that the application and communication language is English. This again has favoured legal scholars of 'international' research topics and with non-Finnish publication records.

Still, the Academy of Finland's evaluation system has been quite well received among legal scholars. Criticism comes mostly from legal scholars who are not interested or motivated in international cooperation, or from scholars who prefer traditional one-man academic work rather than project-based legal research. However, the Academy of Finland's funding system per se - especially with wellresourced Academy professorships and researcher positions - has heightened tension at law faculties between those who are oriented to teach and take care of national (professional) bachelor and master's level education, and those with ambitions to work on international research projects.

\section{THE EVALUATION OF PUBLICATIONS FOR HIRING, PROMOTION AND TENURE DECISIONS}

\subsection{Hiring professors and assistant professors}

The qualifications necessary for academic researchers can be found in the legislation on universities ${ }^{28}$ as well as universities' own regulations - generally without any discipline-specific exceptions. In this section of the chapter, reference is made to the regulations of the University of Helsinki (applied in all disciplines), but the regulations of three other universities with a law faculty differ from these only in minor details. However, in Helsinki, the 'top research' and international cooperation of candidates count more than at the other universities, while the 'factual' qualifications seem to count a bit less: the number of publications is lower and international publications are not necessary.

An appointee to a professorship must hold a doctoral degree and have top-level scholarly qualifications, experience in the supervision of scientific research, and the ability to provide top-level research-based

\footnotetext{
${ }^{28}$ Universities Act (558/2009).
} 
teaching and supervise theses and dissertations. In addition, the appointee must present documentation of international cooperation in his or her field of research. Holders of professorships must also have the skills necessary to serve as an academic leader. When considering the applicant's qualifications, attention is given to scientific publications and other research results of scientific value, as well as teaching merits. Account will also be taken of the applicant's activities in the scientific community, success in obtaining external research funding, international research experience and leadership and interaction skills.

An appointee to the position of assistant professor in the tenure track system, on the other hand, must hold a doctoral degree, have the ability to conduct independent scholarly work and have the teaching skills necessary for the position. In addition, applicants for assistant professorships must demonstrate their ability and motivation for an academic career through publications and other means. Account will also be taken of an applicant's success in obtaining external research funding and international research experience generally. The number and (ranked) quality of publications play an important role when applicants are evaluated.

The appointment procedure for a professorship or an assistant professorship includes many stages, starting with the decisions of the faculty's selection committee (on the details of the call, the legal field to which the position belongs and so on), and the appointment of the so-called 'preparation group' (of four to five professors from the faculty/discipline concerned); continuing with the appointment of external scientific experts (to assess the scientific merits of the best applicants, mainly through CVs and publications records) and the evaluation of teaching skills, with interviews; and ending up with the appointment proposal of the preparation group to the dean and the appointment decision by the university rector.

Scholars appointed to the tenure track will be evaluated for the first time after three to five years of work, according to the criteria agreed between the assistant professor and the faculty. These criteria include a publication plan and plans for funding applications and teaching and supervision.

\subsection{Internal evaluation systems for individual researchers}

Staff salaries at Finnish universities are determined by the 'university salary system', according to which the salary consists of a job-specific pay component and a personal pay component. The jobspecific component is based on the requirements of the position, while the personal component is determined by the employee's work performance. The salary system, however, is a part of the collective agreement system and quite inflexibly reflects employees' improvements.

The main criteria for the assessment of personal performance (based on the electronic evaluation form) are:

- the number and quality (ranking) of academic publications;

- success in obtaining external research funding; 
- international cooperation activities;

- quantity and quality (assessed partly according to student feedback) of teaching activities; and

- societal activities. ${ }^{29}$

The personal performance of an employee is reviewed in an evaluation discussion which takes place (at least every two years) between the employee and his or her superiors (e.g. a head of department or the dean). Factually, a pay increase depends not only on the employee's improvement, but also on the economic framework of the university salary budget and the annual negotiations between the universities and labour organizations.

\section{CONCLUSION}

As a conclusion, one can maintain that a kind of convergence of disciplines can be seen in Finnish academic life. This convergence, however, is one-sided. The publication and evaluation practices of natural sciences are now actively apparent in social sciences and humanities: the writing of journal articles counts for more than the writing of textbooks or other monographs, while texts written in English are considered scientifically and 'economically' more valuable than those written in the national languages. At the same time, evaluation and ranking practices are based more on formal criteria (e.g. the Publication Forum levels) than on substantial criteria. This also applies to the assessment of legal research and individual researchers. Even a change towards 'light' doctoral dissertations may be seen in the near future.

Another change is the widespread implementation of peer review systems in legal publishing. Peer review is also a central criterion for ranking by the Publication Forum. In Finland's small scholarly legal community, however, anonymity is hard to guarantee, even with double-blind peer review. Still, the importance of publications as evidence of academic activity and quality is widely accepted by Finnish legal scholars. Although the Publication Forum rankings are criticized - mainly because of their use, against their foundational premise, to evaluate individual researchers and the dominance of the English language - the application of bibliometric analysis or citation indexes would hardly be accepted among Finnish legal scholars.

In general, today's evaluation culture - where 'internationalization' and external funding are key criteria of success - financially favours faculties and scholars of natural sciences. Within the law faculties, it favours scholars of 'non-dogmatic', non-national topics. For instance, researchers of international law, European law and legal theory have been more successful in obtaining funding from the Academy of Finland than their colleagues. Even foreign scholars (recruited by the universities) have been more successful than their Finnish counterparts. Further, younger scholars who are familiar with

\footnotetext{
${ }^{29}$ Including membership of committees/working groups drafting new legislation, opinions to parliamentary committees and so on.
} 
communicating and publishing in English are often better positioned in evaluations or in resource competitions than their older colleagues.

In fact, legal scholarship has always been international: ideas have travelled, with models adopted and inspiration taken from foreign legal systems. Especially in a small country such as Finland, with two exotic languages, openness towards legal discussions and ideas from outside the country's borders is necessary to achieve good-quality legal research and even legal practice. At the same time, legal norms are drafted and applied in a national environment, by the Parliament, courts or administrative bodies, in the national languages. Legal education in the national languages is also necessary. However, the prevailing evaluation and rating practices are challenging younger scholars' motivation to publish in Finnish or Swedish. There is also a danger that the ideal of research-based teaching may fail, and one group of scholars will be left teaching the core legal topics while the other is active in research and international cooperation. 


\section{BIBLIOGRAPHY}

Academy of Finland, 'Instructions for Reviewing Research Applications - Individual Reviewers' (2016), accessed September 2017 at www.aka.fi/globalassets/20arviointijapaatokset/liitteet/instructions_individual_reviewers_2016.pdf

Julkaisufoorumi, 'Publication Forum' (Julkaisufoorumi, 12 May 2016), accessed September 2017 at www.julkaisufoorumi.fi/en/publication-forum

Letto-Vanamo P, Legal Education as a Channel to Social Elite (Scientia Danica Series H 2017)

Micklitz H-W (ed), The Many Concepts of Social Justice in European Private Law (Edward Elgar Publishing 2011)

Saarela M, Kärkkäinen T, Lahtonen T and Rossi T, 'Expert-based versus citation-based ranking of scholarly and scientific publication channels' (2016) 10 Journal of Informetrics 693

Saari S and Moilanen A (eds), 'RC-Specific Evaluation of Law -Researchers at the Faculty of Law' (2012) 20, accessed September 2017 at

www.helsinki.fi/julkaisut/aineisto/rc_evaluation2012/hallinnon_julkaisuja_80_125_2012.pdf

Wilhelmson T, Moëll C and Shaw J, 'RAE 2015 of the University of Turku. Peer-Evaluation Report' (2015), accessed September 2017 at www.utu.fi/fi/Tutkimus/tutkimuksen-

kokonaisarviointi/arviointiaineisto/vertaisarviointi/Documents/law/oikeustieteellinen_tdk.pdf 